\title{
Overexpression of Nerve Growth Factor in Skin Selectively Affects the Survival and Functional Properties of Nociceptors
}

\author{
C. L. Stucky, ${ }^{1}$ M. Koltzenburg, ${ }^{1}$ M. Schneider, ${ }^{1}$ M. G. Engle, ${ }^{2}$ K. M. Albers, ${ }^{3}$ and B. M. Davis ${ }^{2}$ \\ ${ }^{1}$ Department of Neurology, University of Würzburg, D-97080 Würzburg, Germany, and Departments of ${ }^{2}$ Anatomy and \\ Neurobiology and ${ }^{3}$ Pathology, University of Kentucky, Lexington, Kentucky 40536
}

\begin{abstract}
Mice that overexpress nerve growth factor (NGF-OE) in the skin have double the normal number of cutaneous sensory neurons, have increased innervation of the skin and spinal cord, and are hyperalgesic. Here, we have asked whether the increased cutaneous NGF level results in a selective survival of only certain functional types of neurons and whether it changes the properties of cutaneous neurons. Using electron microscopy, we show that the number of both myelinated and unmyelinated nociceptors increases substantially in NGF-OE mice by a factor of 3.3 and 1.5 , respectively. Using extracellular recordings from single units, we demonstrate that large myelinated $(A \beta)$ fibers are unchanged in prevalence and receptive properties. In contrast, among thin myelinated $(A \delta)$ fibers, the percentage of nociceptors increased from a normal 65 to $97 \%$, consistent with a selective survival of nociceptors during embryogenesis. These afferents showed a twofold increase in their mechanical
\end{abstract}

Peripheral sensory neurons are over-produced during embryonic development in mammals. Nearly half of these neurons undergo programmed cell death, leaving the appropriate number and functional types in the adult animal. Programmed cell death occurs at the same time that growing sensory axons make functional connections with their peripheral targets in the embryo. The ability of neurons to acquire limited amounts of neurotrophic factors from target tissues regulates the magnitude and specificity of neuronal survival (for review, see Lewin and Barde, 1996).

Studies of mice that lack a specific neurotrophin ligand or receptor have demonstrated that functionally distinct classes of peripheral sensory neurons depend on specific neurotrophic factors for survival (Snider, 1994). Nociceptors, sensory neurons that respond to actual or potentially tissue-damaging stimuli, depend on nerve growth factor (NGF) for survival (Crowley et al., 1994; Smeyne et al., 1994). NGF is expressed at high levels in the skin between embryonic day 11 (E11) and E14, after which it falls sharply (Davies et al., 1987). Because the drop in NGF coincides with the death of approximately half of all sensory neurons (Davies and Lumsden, 1984), we hypothesized that enhanced

Received March 12, 1999; revised July 7, 1999; accepted July 12, 1999.

This work was supported by the Deutsche Forschungsgemeinschaft, Sonderforschungsbereich 353 (M.K.), NS31826 (B.M.D.), and NS33730 (K.M.A.) and a collaborative grant from NATO. We thank Dr. Gary Lewin for helpful discussions.

Correspondence should be addressed to Dr. Martin Koltzenburg, Department of Neurology, University of Würzburg, Josef-Schneider-Strasse 11, D-97080 Würzburg, Germany. E-mail: koltzenburg@mail.uni-wuerzburg.de

Dr. Stucky's present address: Department of Cell Biology, Neurobiology. and Anatomy, Medical College of Wisconsin, Milwaukee, WI 53226.

Copyright (C) 1999 Society for Neuroscience $0270-6474 / 99 / 198509-08 \$ 05.00 / 0$ responsiveness, but their heat responsiveness remained normal. Among unmyelinated (C) fibers, there was a profound increase in the percentage of heat responsive neurons from a normal 42 to $96 \%$. This change cannot be accounted for by a selective survival of heat-sensitive neurons. Unmyelinated nociceptors increased fourfold in their thermal responsiveness but decreased in mechanical responsiveness. Therefore, targetderived NGF selectively rescues nociceptors during the period of programmed cell death with different efficacy for thin myelinated or unmyelinated fibers. NGF also affects the response to noxious heat or mechanical stimuli in each group differently, implying specific regulations of transduction processes rather than general changes of excitability.

Key words: neurotrophin; p75; pain; programmed cell death; sensory neuron; trk

expression of NGF during this critical time in development would selectively rescue nociceptors.

NGF has also been shown to regulate the phenotype of sensory neurons. Sequestration of endogenous NGF induces neurons that would normally become myelinated nociceptors to instead become low-threshold D-hair receptors (Ritter et al., 1991). Injections of neonatal rats with NGF also increases the mechanical sensitivity of myelinated nociceptors (Lewin et al., 1993) and the heat sensitivity of unmyelinated nociceptors (Lewin and Mendell, 1994). Thus, we hypothesized that embryonic overexpression of NGF would also alter the functional properties of nociceptors.

Transgenic mice have been generated that overexpress NGF in skin under the control of the epidermal keratin (K14) gene promoter (Albers et al., 1994). These NGF-overexpressing (NGF-OE) mice begin to express elevated levels of NGF at approximately E11 and continue throughout adulthood, maintaining high levels of NGF in skin. Previous studies have shown that NGF-OE mice have twice the normal number of sensory neurons in trigeminal and dorsal root ganglia and exhibit marked hypertrophy of peripheral axons and cell bodies (Albers et al., 1994; Jhaveri et al., 1996; Mendelson et al., 1996; Davis et al., 1997; Goodness et al., 1997). NGF-OE mice also have increased innervation of the skin and dorsal horn by calcitonin gene-related peptide (CGRP)-positive fibers (Albers et al., 1994; Mendelson et al., 1996; Davis et al., 1997), which are likely to be nociceptors (Lawson, 1992). Behaviorally, NGF-OE mice are hyperalgesic to mechanical (Davis et al., 1993) and thermal (B. M. Davis and K. M. Albers, unpublished data) stimuli, yet none of these studies has directly determined whether nociceptors are selectively affected or whether the enhanced levels of NGF in NGF-OE mice 
change the functional properties of myelinated or unmyelinated nociceptors. Therefore, we used electrophysiological and morphological techniques to directly determine the prevalence and properties of all types of sensory neurons in a purely cutaneous nerve from adult NGF-OE and control mice.

\section{MATERIALS AND METHODS}

Transgenic mice overexpressing NGF in the skin under the control of the K14 keratin promoter (Albers et al., 1994) were used. Mice were screened for the presence of the K14-NGF transgene using slot-blot analysis of DNA isolated from tail samples. The background strain $(\mathrm{Bl} / \mathrm{C} 3 \mathrm{H})$ in which NGF-OE mice were generated was used as the control strain.

Nerve fiber counts. Mice were anesthetized and perfused transcardially with $4.0 \%$ paraformaldehyde and $2.0 \%$ glutaraldehyde in $0.1 \mathrm{M}$ phosphate buffer (PB) (NGF-OE, $n=3$; control, $n=3$ ). Segments of the saphenous nerve from the midthigh were post-fixed, washed in $\mathrm{PB}$, dehydrated in graded alcohols, embedded in Spurr's resin (EM Corp., Chestnut Hill, MA), and cut at $0.7-0.8 \mathrm{~nm}$ on an ultramicrotome. Ultrathin sections were stained with lead citrate and uranyl acetate, photographed on an electron microscope (EM) (H7000; Hitachi Ltd., Tokyo, Japan), and the images were assembled into montages. Myelinated and unmyelinated nerve fibers were analyzed with a computer using NIH Image 1.4 software. The entire nerve was analyzed for axon counts of myelinated and unmyelinated fibers, and 150 axons were measured in each group for the axon diameters. NGF is also known to increase the survival of sympathetic neurons (Johnson et al., 1980; Ruit et al., 1990; Davis et al., 1996), and some of these sympathetic neurons become myelinated in NGF-OE mice. Therefore, to determine the contribution of sympathetic fibers to the number of myelinated axons, we surgically removed the upper three lumbar sympathetic ganglia from adult NGF-OE $(n=2)$ of one side under brief anesthesia of Avertin. The sympathetic contribution to the saphenous nerve has not been reported for the mouse; however, in rat, the upper three lumbar sympathetic ganglia contain the sympathetic neurons that project into the saphenous nerve (Baron et al., 1988). In the experiments reported here, there was no visible fusion between the ganglia of both sides. Five days after sympathectomy, mice were reanesthetized and perfused, and sections of the ipsilateral and contralateral saphenous nerve were removed, fixed, cut, and analyzed as described above.

Neurophysiological recordings. An in vitro skin-nerve preparation was used to record from single, functionally identified cutaneous sensory neurons in NGF-OE $(n=8)$ and control $(n=8)$ mice (Koltzenburg et al., 1997). The saphenous nerve with its cutaneous innervation territory was removed from the hindlimb, placed corium side up in a tissue bath, and superfused $(15 \mathrm{ml} / \mathrm{min})$ with oxygen-saturated, synthetic interstitial fluid containing (in mM): $123 \mathrm{NaCl}, 3.5 \mathrm{KCl}, 0.7 \mathrm{MgSO}_{4}, 1.7 \mathrm{NaH}_{2} \mathrm{PO} 4$, $2.0 \mathrm{CaCl}_{2}, 9.5$ sodium gluconate, 5.5 glucose, 7.5 sucrose, and 10 HEPES, $\mathrm{pH} 7.45 \pm 0.05$, at $32^{\circ} \pm 0.5^{\circ} \mathrm{C}$. The nerve was desheathed, and extracellular recordings were made from functionally isolated afferent fibers using gold wire electrodes. Action potentials were acquired using a low-noise differential amplifier, stored on a personal computer, and later analyzed with a template-matching program (Forster and Handwerker, 1990).

Fibers were first identified by probing the skin with a glass rod, a stimulus that is known to activate all mechanically sensitive units (Kress et al., 1992; Koltzenburg et al., 1997). The conduction velocity of each mechanosensitive fiber was determined by electrically stimulating the receptive field with supramaximal square wave pulses of $0.1-1.0 \mathrm{msec}$ duration using a Teflon-coated steel electrode (1-5 M $\Omega$ impedance, shaft diameter of $300 \mu \mathrm{m}$, uninsulated tip diameter of 5-10 $\mu \mathrm{m})$. Units conducting faster than $10 \mathrm{~m} / \mathrm{sec}$ were classified as large myelinated $\mathrm{A} \beta$ fibers, units conducting between 1.2 and $10 \mathrm{~m} / \mathrm{sec}$ were classified as thin myelinated $\mathrm{A} \delta$ fibers, and units conducting slower than $1.2 \mathrm{~m} / \mathrm{sec}$ were unmyelinated C fibers (Koltzenburg et al., 1997).

The mechanical threshold was determined using calibrated von Frey filaments (self-constructed from nylon thread of various diameters, tip diameter of $0.8 \mathrm{~mm}$, range of force of $1-362 \mathrm{mN}$ ). Mechanical responsiveness was then systematically characterized by using a computerdriven, feedback-controlled stimulator that applied a standard series of ramp and sustained force stimuli (200 msec rise time, $10 \mathrm{sec}$ duration, plateau force of 5-300 mN, interstimulus interval of $60-120 \mathrm{sec}$ ). Data were analyzed for $11 \mathrm{sec}$ beginning with the onset of force.

Based on their response pattern to mechanical stimuli, myelinated fibers could be clearly classified in both strains of mice as described previously into four subpopulations (Koltzenburg et al., 1997; Stucky and Koltzenburg, 1997). Because large myelinated fibers tend to be sampled more frequently than thin myelinated or unmyelinated fibers, the proportion of each subtype of fiber encountered within each category $(\mathrm{A} \beta$, $\mathrm{A} \delta, \mathrm{C})$ was determined. Large myelinated $(\mathrm{A} \beta)$ fibers had low mechanical thresholds and were classified as either slowly adapting (SA) if they responded tonically to sustained force or rapidly adapting (RA) if they responded only at the onset or offset of the force. Thin myelinated (A $\delta)$ fibers were classified as either A fiber mechanonociceptors (AM nociceptors) if they responded tonically to high-intensity force or D-hair receptors if they were activated by very low mechanical force $(<1 \mathrm{mN})$ and responded with high frequency to the onset and offset of force. Unmyelinated C fibers and AM nociceptors were tested first for their response properties to mechanical stimuli and then further classified by their response properties to noxious thermal stimuli.

Heat sensitivity was determined by applying a linear heat ramp (32$47^{\circ} \mathrm{C}$ in $15 \mathrm{sec}$ ) with a feedback-controlled lamp focused through the translucent bottom of the tissue bath onto the epidermal side of the skin. The resulting temperature was measured at the corium side (top) of the skin by a thermocouple inserted into the skin. The temperature at the corium side of the skin corresponds to an $\sim 5 \mathrm{C}^{\circ}$ higher temperature on the epidermal surface (Reeh, 1986). Therefore, the maximal heat stimulus given to each nociceptor was $52^{\circ} \mathrm{C}$, a temperature that has been shown to maximally activate heat-sensitive $\mathrm{AM}$ and $\mathrm{C}$ fiber nociceptors in rodents without damaging the skin preparation (Reeh, 1986; Koltzenburg et al., 1997). Cold stimuli were given by isolating the receptive field with a metal ring and applying a bolus of ice-cold synthetic interstitial fluid for $10 \mathrm{sec}$, resulting in a minimum skin temperature of $4-8^{\circ} \mathrm{C}$. Care was taken to avoid mechanical stimulation during the thermal stimuli. A fiber was considered to be heat- or cold-sensitive if three or more action potentials were evoked during the stimulation.

Statistical analysis. All values are given as mean \pm SEM or as median and interquartile range of the 25 th and 75 th percentile. Parametric and nonparametric statistical tests were performed as appropriate after fulfillment of all necessary prerequisites using the Statistica software package (StatSoft, Tulsa, OK).

\section{RESULTS}

\section{Myelinated and unmyelinated sensory axons are increased in the saphenous nerve of NGF-OE mice}

Overexpression of NGF in the skin resulted in a 1.8-fold increase in the total number of axons in the purely cutaneous saphenous nerve, corresponding to the twofold increase in the number of sensory neurons reported previously (Albers et al., 1994; Jhaveri et al., 1996, Mendelson et al., 1996). This indicates that the increase in axon profiles in the saphenous nerve is caused by an increase in cell number and not axonal branching. Interestingly, this increase was attributable to a significant ( $p<0.001 ; t$ test) 3.3-fold increase in the number of myelinated axons from $508 \pm$ 3 to $1701 \pm 168$ and a significant $(p<0.001 ; t$ test $) 1.5$-fold increase in the number of unmyelinated sensory fibers from $2482 \pm 151$ to $3739 \pm 340$ axons. This means that there is an increase in the percentage of myelinated fibers from $17 \%$ in wild-type animals to $31 \%$ in NGF-OE mice. In addition, both myelinated and unmyelinated axons were increased in diameter (Fig. $1 A, B$ ). The hypertrophy of unmyelinated axons was particularly dramatic, because most of the unmyelinated axons in NGF-OE mice were larger than any of the unmyelinated axons in control mice. This increase in size was further reflected in the mean axonal diameter of transgenic unmyelinated fibers that was almost twice as large as controls (NGF-OE, $0.89+0.01 \mu \mathrm{m}$; control, $0.53+0.01 \mu \mathrm{m} ; p<0.001$; Kolmogorov-Smirnoff test). The mean diameter of the myelinated axons (without the myelin sheath) in NGF-OE mice was also increased compared with controls, although to a lesser extent (NGF-OE, $2.83+0.08 \mu \mathrm{m}$; control, $2.14+0.08 \mu \mathrm{m} ; p<0.001$; Kolmogorov-Smirnov test). Sympathetic neurons also depend on NGF for survival (Gorin 
A

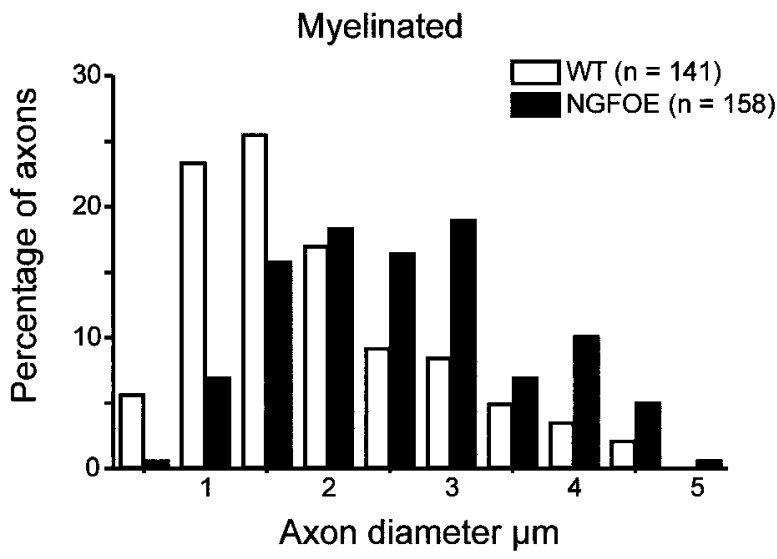

B

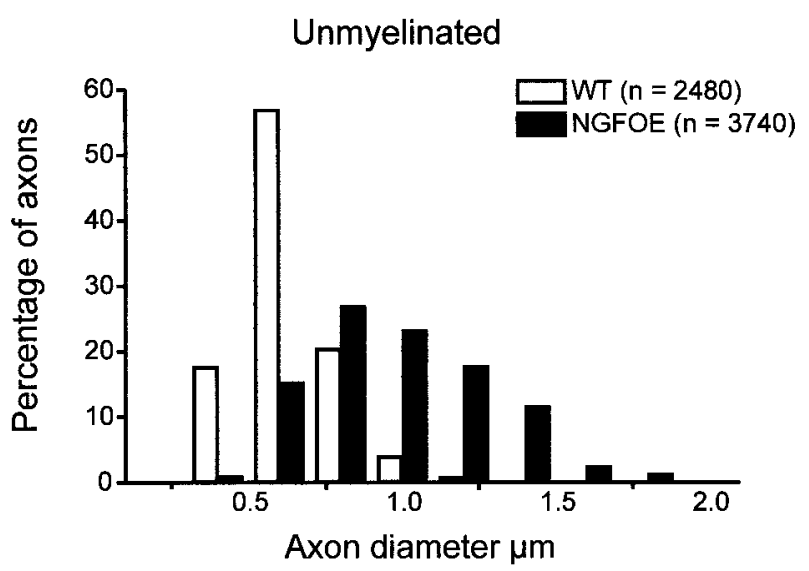

Figure 1. Distribution of myelinated $(A)$ and unmyelinated $(B)$ axons in the saphenous nerve of control and NGF-OE mice (3 animals in each group). For myelinated axons, the diameters include the nerve axon only, without the myelin sheath. Note that both axon distributions from NGF-OE animals are shifted to the right, reflecting significant hypertrophy of myelinated and unmyelinated fibers.

and Johnson, 1980; Ruit et al., 1990), and increased levels of NGF have been shown to increase the density of sympathetic axons in the periphery (Olson, 1967; Davis et al., 1994, 1996). NGF-OE mice have occasional myelinated postganglionic sympathetic axons that are not found in normal animals (Davis, unpublished observation). Therefore, we repeated the myelinated axon counts in NGF-OE mice that had undergone unilateral lumbar sympathectomies $(n=2)$ to determine whether the increase in myelinated fibers could be attributable to a contribution of sympathetic neurons. Only small decreases on the order of $10 \%$ were observed (mouse 1, 1423 myelinated axons contralateral to lesion, 1237 ipsilateral to lesion; mouse 2, 1543 axons contralateral to lesion, 1440 ipsilateral to lesion). These results suggest that myelinated sympathetic axons did not contribute significantly to the number of myelinated axons in NGF-OE mice and that the increase in myelinated fibers was primarily caused by sensory neurons.

\section{Conduction velocity of sensory neurons remains unaltered in NGF-OE mice}

Despite the hypertrophy of axons in NGF-OE mice, the distribution of the conduction velocities of both myelinated (NGF-OE, $9.6 \pm 0.6 \mathrm{~m} / \mathrm{sec}$; control, $10.2 \pm 1.1 \mathrm{~m} / \mathrm{sec} ; p>0.5 ; t$ test $)$ and
A

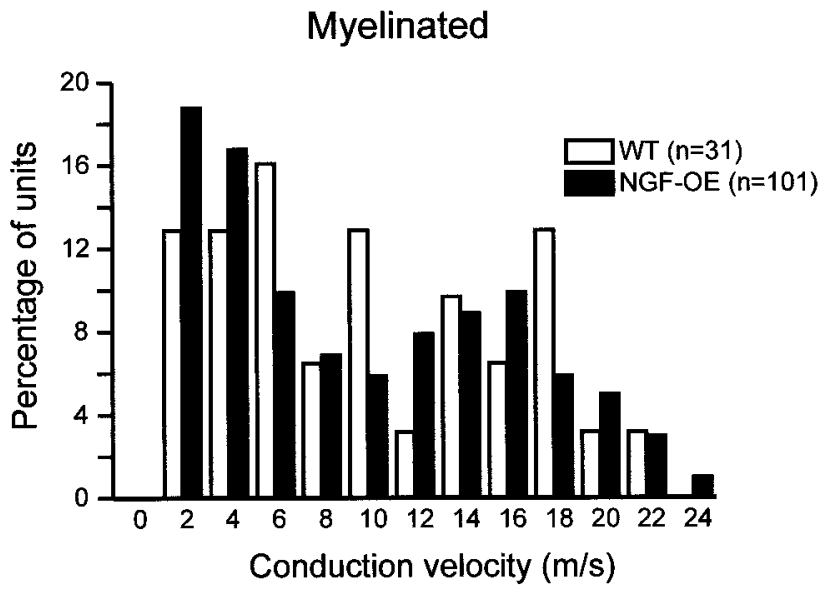

B

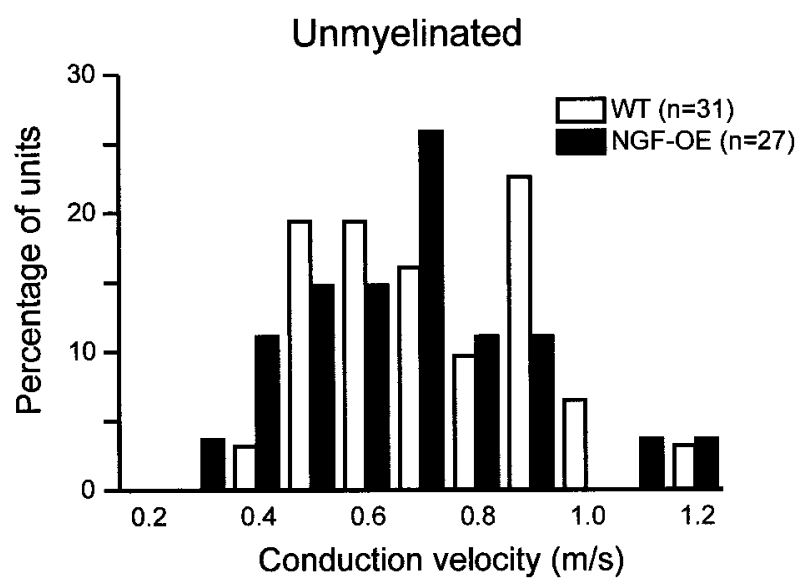

Figure 2. Distribution of recorded myelinated $(A)$ and unmyelinated $(B)$ fibers by conduction velocity in control and NGF-OE mice. Units conducting $>1.2 \mathrm{~m} / \mathrm{sec}$ were classified as myelinated. Numbers in parentheses indicate the number of units recorded. Note that the distribution of conduction velocities between NGF-OE and control mice did not differ for either class of fiber.

unmyelinated (NGF-OE, $0.63 \pm 0.04 \mathrm{~m} / \mathrm{sec}$; control, $0.67 \pm 0.03$; $p>0.2 ; t$ test) axons was not significantly different (Fig. 2). Measurement of myelinated conduction velocities for both control and NGF-OE mice (Fig. $2 A$ ) appear to be bimodal, with a minimum occurring (between the two peak values) at 10-12 $\mathrm{m} / \mathrm{sec}$, as reported previously (Koltzenburg et al., 1997). The similarity in the overall distribution of conduction velocities for both strains suggests that the cutoff point $(10 \mathrm{~m} / \mathrm{sec})$ for distinguishing $\mathrm{A} \delta$ from $\mathrm{A} \beta$ fibers is valid.

For myelinated axons, both axon diameter and myelin thickness correlates positively with conduction velocity (Waxman, 1980). Therefore, we also examined myelin thickness in control and NGF-OE axons (Fig. 3). Although there was a significant linear correlation between the thickness of myelin and the axon diameter (control, $r=0.76$; $p<0.01$; NGF-OE, $r=0.83$; $p<$ 0.001 ) for both genotypes, NGF-OE axons had consistently thinner myelin for a given axonal diameter. This fact is also reflected by calculation of the G-ratio (which equals the axon diameter/ total diameter of axon plus myelin sheath). The mean G-ratio for control mice was $0.67+.005$, whereas it was $0.75+0.005$ for NGF-OE mice ( $p<0.001 ; t$ test). Thus, in NGF-OE mice, the 


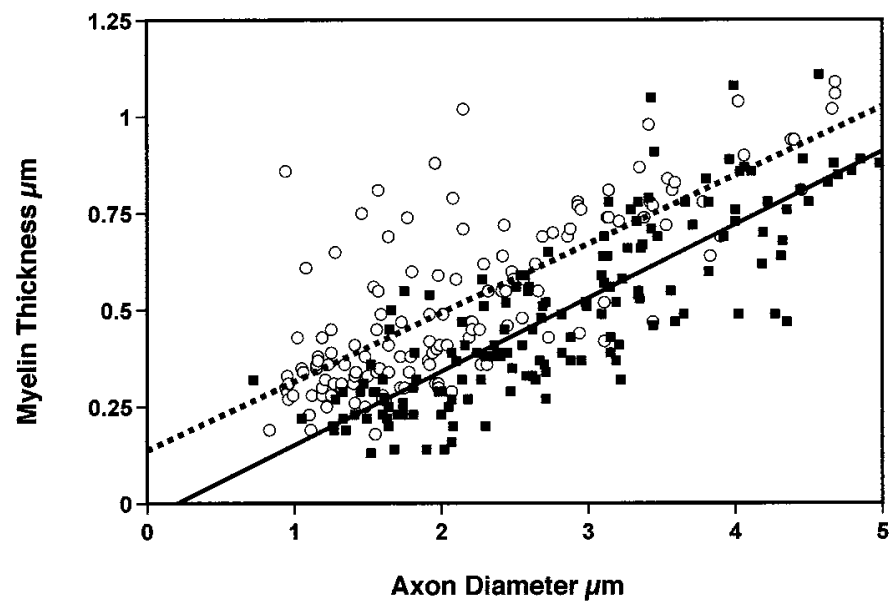

Figure 3. Regression analysis of myelin thickness versus the axon diameter for control (open circles, dashed line) and NGF-OE mice (filled squares, continuous line) (3 animals in each group). Note that both control and NGF-OE axons exhibit significant correlation between myelin thickness and axon diameter. However, NGF-OE mice exhibit overall a significantly thinner myelin sheath for a give axonal diameter than control mice do.

increase in the diameter of the axon was not accompanied by the same proportional increase in the diameter of the myelin thickness that was observed in control mice.

\section{Non-nociceptive mechanoreceptors are unchanged in NGF-OE mice}

Because the counts of axons in the saphenous nerve showed that myelinated and unmyelinated axons were increased in NGF-OE mice, electrophysiological techniques were used to directly determine which functional subtypes of afferent neurons were affected. Among the large myelinated, low-threshold $\mathrm{A} \beta$ fibers, there was no change in the proportion of SA or RA fibers encountered compared with controls (Fig. 4A). There was also no significant difference in the mechanical stimulus-response properties of SA or RA fibers in NGF-OE mice (Fig. $4 B, C$ ). There was also no difference in the conduction velocity of SA fibers (NGF-OE, $15.9 \pm 0.8 \mathrm{~m} / \mathrm{sec}$; control, $15.2 \pm 1.9 \mathrm{~m} / \mathrm{sec} ; p>0.5 ; t$ test $)$ or RA fibers (NGF-OE, $16.6 \pm 0.8 \mathrm{~m} / \mathrm{sec}$; control, $16.0 \pm 0.6 \mathrm{~m} / \mathrm{sec} ; p>$ 0.5 ; $t$ test). These data suggest that the increase in the number of myelinated axons in NGF-OE saphenous nerve is not attributable to an increase in SA or RA fibers and that the receptive properties of these units is not influenced by the excess amount of NGF.

\section{Myelinated nociceptors increase in number}

In contrast to the $\mathrm{A} \beta$ fibers, both $\mathrm{A} \delta$ and $\mathrm{C}$ fiber nociceptors were clearly affected in NGF-OE mice. First, the percentage of mechanosensitive $\mathrm{A} \delta(\mathrm{AM})$ nociceptors encountered during neurophysiological recordings was significantly increased. In control mice used in the present study, AM fibers constituted $65 \%$ of all A $\delta$ fibers. This percentage of AM fibers is identical to that recorded in two other strains of control mice (Airaksinen et al., 1996; Stucky et al., 1998). In NGF-OE mice, however, AM nociceptors accounted for $97 \%$ of all A $\delta$ fibers encountered $(p<$ $0.001 ; \chi^{2}$-test) (Fig. 5A). These results are consistent with the notion that the total increase of myelinated axons were caused by a selective survival of AM nociceptors.
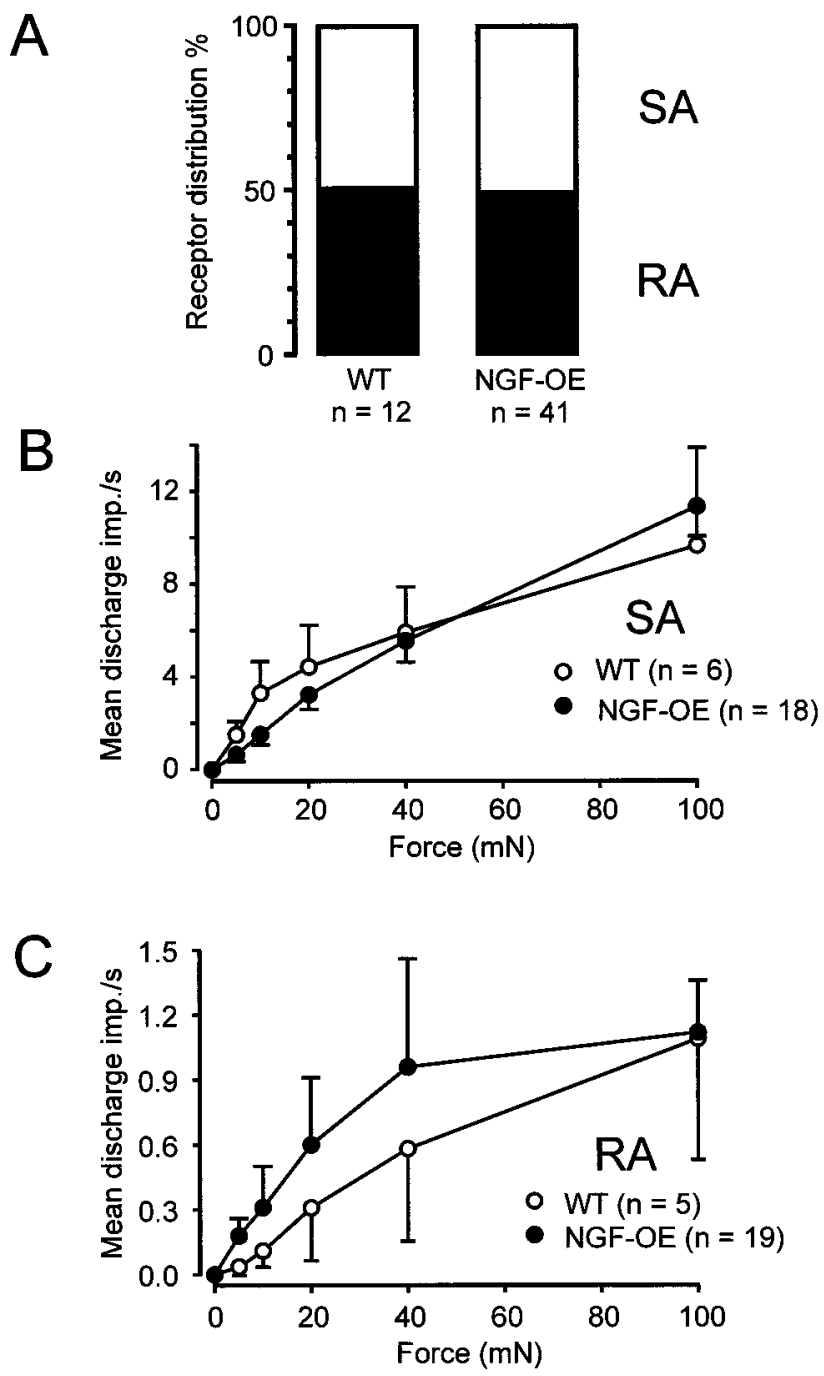

Figure 4. $A$, Proportion of SA and RA A $\beta$ fibers encountered in control and NGF-OE mice. Mechanical stimulus-response properties of SA fibers $(B)$ and RA fibers $(C)$ to constant force stimuli. There were no significant differences in the mechanical responsiveness of either type of fiber (SA fibers, $F_{(1,157)}=1.35 ; p>0.1$; RA fibers, $F_{(1,162)}=0.125 ; p>0.5$; ANOVA).

\section{Sensitivity for mechanical, but not for heat, stimuli increases in myelinated nociceptors}

Not only were AM nociceptors increased in survival but individual AM fibers also showed significantly increased mechanical responsiveness (Fig. 5B) that became particularly evident for suprathreshold stimuli. Application of $100-300 \mathrm{mN}$ sustained force evoked discharge rates in NGF-OE AM fibers that were twice as high as those in controls. However, the NGF-induced enhanced responsiveness was not a general attribute for all noxious modalities because the heat sensitivity of AM fibers in NGF-OE mice was unchanged compared with controls (Fig. 5C). There was no significant difference in the percent of AM fibers responding to heat, the threshold for a response, or in the mean spikes per heat stimulus (Table 1). Interestingly, there was a significant increase in the number of AM fibers in NGF-OE mice responding to a noxious cold stimulus, indicating that the cellular elements that mediate thermal transduction are differentially regulated for cold and heat in A $\delta$ nociceptors.

A small number of AM fibers in NGF-OE mice had ongoing 
A

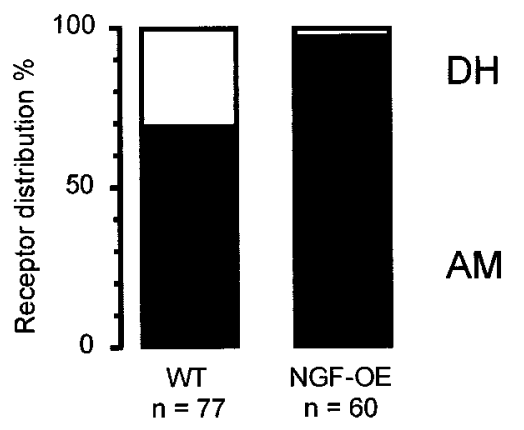

B
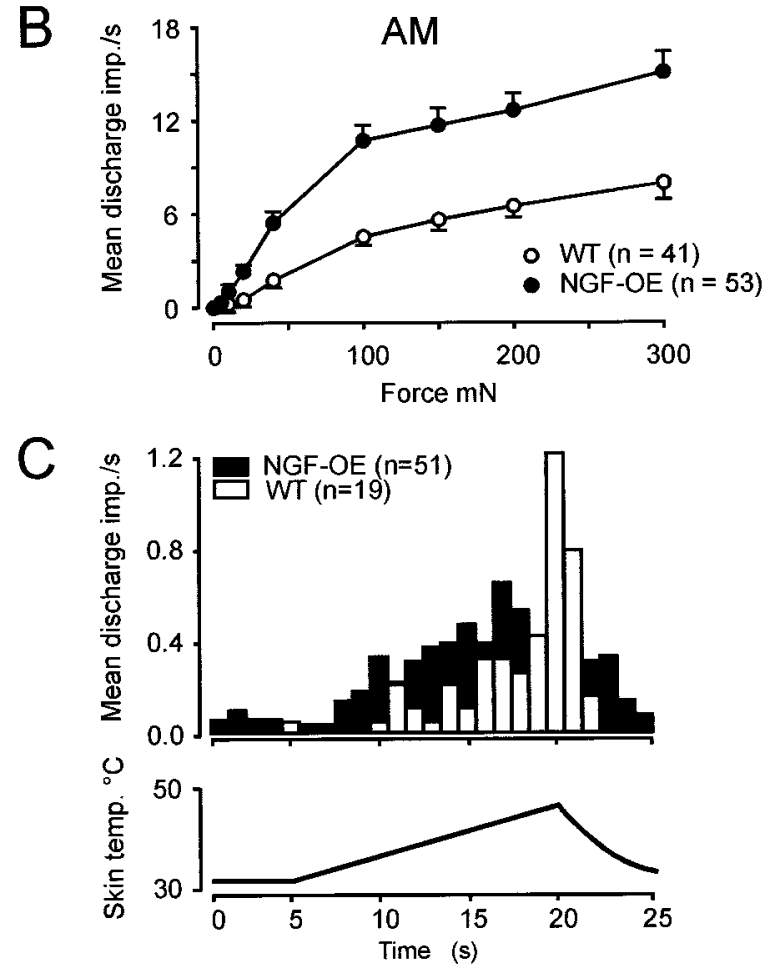

Figure 5. A, Prevalence of AM nociceptors and D-hair receptors in control and NGF-OE mice. $B$, Mechanical stimulus-response properties of AM nociceptors in control and NGF-OE mice. Mechanical responsiveness of AM nociceptors in NGF-OE mice was significantly higher than in control mice $\left(F_{(1,715)}=19.8 ; p<0.001\right.$; ANOVA). $C$, Average action potentials per second during $15 \mathrm{sec}$ heat ramp stimulus for all AM fibers tested with heat stimuli. There was no significant difference between control and NGF-OE mice.

discharge $(12 \% ; 7$ of 58$)$, whereas none of the AM fibers in control mice showed ongoing activity ( 0 of 19$)(p>0.1$; Fisher's exact test). Both heat-sensitive (2 of $7 ; 29 \%)$ and heat-insensitive (5 of 7; 71\%) AM fibers exhibited spontaneous activity. However, all of the NGF-OE AM fibers with ongoing activity had conduction velocities that were well below the average of AM fibers with no ongoing activity (mean conduction velocity of AM fibers with ongoing activity, $2.9 \pm 0.5 \mathrm{~m} / \mathrm{sec} ; n=7$; vs AM fibers with no ongoing activity, $5.2 \pm 0.5 \mathrm{~m} / \mathrm{sec} ; n=51 ; p<0.05 ; t$ test).

\section{Sensitivity for heat increases and mechanical stimuli decreases in unmyelinated nociceptors}

C fiber nociceptors were also affected in NGF-OE mice. In addition to a $50 \%$ increase in the total number of $\mathrm{C}$ fibers in the saphenous nerve, nearly every $\mathrm{C}$ fiber $(96 \%)$ in NGF-OE mice responded to heat (Table 1). Furthermore, the number of heat- evoked action potentials per $\mathrm{C}$ fiber was increased fourfold in NGF-OE mice (Table 1, Fig. 6B). In addition, $\mathrm{C}$ fibers in NGF-OE mice exhibited spontaneous activity that was much higher than that in controls. In fact, $60 \%$ of $\mathrm{C}$ fibers in NGF-OE (16 of 27) had ongoing activity compared with $6.5 \%$ of those in control mice ( 2 of $31 ; p<0.001 ; \chi^{2}$-test). In direct contrast to AM nociceptors, which were increased in mechanical responsiveness, the mean firing frequency of NGF-OE C fibers to strong mechanical stimuli was reduced by half (Fig. 6A), providing another example of the dissociation between mechanical and thermal responsiveness in nociceptors. Also, in contrast to the finding of increased cold sensitivity in A $\delta$ fibers, cold sensitivity was unaltered in $\mathrm{C}$ fibers. Together, the differential regulation of mechanical, heat and cold sensitivity, as well as the different prevalence of ongoing activity, suggests that increased availability of NGF in mice regulates the receptive properties of $\mathrm{C}$ and $\mathrm{A} \delta$ fibers differentially.

\section{DISCUSSION}

The principal finding of our study is that increased expression of NGF in the skin from the period of programmed cell death through adulthood selectively rescues myelinated and unmyelinated nociceptors from cell death. Furthermore, NGF specifically alters the receptive properties of nociceptors, and responsiveness to mechanical and thermal stimuli is differentially regulated in subpopulations of thin myelinated and unmyelinated nociceptors.

\section{NGF leads to an increase in the number of nociceptors that affects thin myelinated and unmyelinated fibers differently}

Ultrastructural analysis of the saphenous nerve in this study revealed a 1.8-fold increase in axon number, which is consistent with the twofold increase in the total number of sensory neurons in the dorsal root and trigeminal ganglia (Albers et al., 1994; Jhaveri et al., 1996; Mendelson et al., 1996), indicating that the increase in the number of axon profiles is not the consequence of sprouting. Combining results from nerve counts and electrophysiological recordings, we can conclude that mechanosensitive afferents with large myelinated neurons were unaffected by the increased availability of NGF. The lack of effect on large myelinated neurons is in agreement with previous examination of NGF-OE mice that found no change in the Merkel cells (Davis et al., 1997), which depend on their postnatal survival on the innervation by SA fibers and NT-3 (Airaksinen et al., 1996). Whereas the properties and prevalence of slowly and rapidly adapting neurons was unaltered, the increase in cutaneous nociceptors observed in this study is consistent with the fivefold increase observed in trkA-positive sensory neurons in NGF-OE mice (Goodness et al., 1997). NGF-OE mice also have increased innervation of the skin and dorsal horn by CGRP-positive fibers (Albers et al., 1994; Mendelson et al., 1996; Davis et al., 1997), which are likely to be nociceptors (Lawson, 1992).

In absolute numbers, there was an approximately equal increase of 1200 axons for both myelinated and unmyelinated fibers, and, as evidenced by the results of the sympathectomy, the vast majority of these fibers are afferents. However, overexpression of NGF has a differential effect on unmyelinated and thinly myelinated fibers. There are $\sim 300 \mathrm{~A} \delta$ axons in the saphenous nerve of wild-type mice. The total number of AM nociceptors has been calculated to be 200 ( $65 \%$ of all A $\delta$ fibers), and the total number of D-hair receptors is $\sim 100$ (35\% of A $\delta$ fibers) (Koltzenburg et al., 1997). Assuming that the surplus of myelinated axons in 


\begin{tabular}{lll}
\hline \multicolumn{2}{l}{ Table 1. Mechanical and thermal responsiveness of nociceptors } & \\
& WT & NGF-OE \\
\hline A fibers & & \\
Median (interquartile range) von Frey threshold $[\mathrm{mN}]$ & $4.0(5.2)$ & $5.6(5.2)$ \\
\% Units responding to heat & $21 \%(4$ of 19$)$ & $29 \%(15$ of 51$)$ \\
Mean \pm SEM threshold for heat response $\left[{ }^{\circ} \mathrm{C}\right]$ & $43.6 \pm 2.6$ & $39.7 \pm 1.2$ \\
Mean \pm SEM spikes per heat simulus for all units & $4.1 \pm 2.7$ & $4.8 \pm 1.8$ \\
\% Units responding to cold & $10 \%(1$ of 10$)$ & $46 \%(6$ of 13$)$ \\
C fibers & & \\
Median (interquartile range) von Frey threshold $[\mathrm{mN}]$ & $5.6(4.0)$ & $8.0(5.6)$ \\
$\%$ Units responding to heat & $42 \%(10$ of 24$)$ & $96 \%(24 \text { of } 25)^{* *}$ \\
Mean \pm SEM threshold for heat response $\left[{ }^{\circ} \mathrm{C}\right]$ & $39.2 \pm 1.4$ & $37.3 \pm 0.7$ \\
Mean \pm SEM spikes per heat simulus for all units & $10.4 \pm 3.8$ & $41.1 \pm 7.6^{\# \# \#}$ \\
$\%$ Units responding to cold & $33.3 \%(4$ of 12$)$ & $50 \%(5$ of 10$)$ \\
\hline
\end{tabular}

**indicates that percent of fibers in NGF-OE animals is significantly different from that in controls $\left(p<0.01 ; \chi^{2}\right.$ test $)$. \#\#\# indicates that the mean number of spikes for fibers in NGF-OE animals is significantly different from that in controls $(p<0.001 ; t$ test). All other measures do not differ significantly between wild type (WT) and NGF-OE.

NGF-OE mice is the consequence of a selective survival of AM nociceptors, there would be 1400 AM fibers and 100 D-hairs. This would result in an AM fiber/D-hair ratio of $93 \%$, which is close to the observed ratio of $97 \%$. Although this altered ratio of AM fibers/D-hairs could be attributable to phenotypic switching, previous experiments suggest that this is unlikely; injection of neonatal rats with NGF does not induce D-hair receptors, which depend on NT-3 (Airaksinen et al., 1996) and NT-4 (Stucky et al., 1998) for survival to undergo phenotypic switching and become AM nociceptors (Lewin et al., 1993).

Among the unmyelinated fibers projecting into a cutaneous nerve in rodents, only $20 \%$ are sympathetic fibers (Baron et al., 1988), and this means that there are 2000 unmyelinated afferent fibers in the saphenous nerve of wild-type mice. The increase of 1200 unmyelinated axons in NGF-OE mice, therefore, translates into an increase of only $60 \%$. This suggests that the survivalpromoting effects of NGF are much higher for neurons with thin myelinated axons (which exhibited a sevenfold increase) than for unmyelinated nociceptors. However, unlike the increase in AM nociceptors, the increased percentage of heat-sensitive $\mathrm{C}$ fibers cannot be explained by a selective survival effect. In control saphenous nerve, $\sim 800$ units (40\% of 2000 neurons) are mechanoheat-sensitive nociceptors. In NGF-OE mice, even if the entire increase in $\mathrm{C}$ fibers were caused by a selective increase in heat-sensitive fibers, this would result only in $62.5 \%$ (2000 of 3200) of all $\mathrm{C}$ fibers being heat-sensitive. This percent is much lower than the observed percentage of $96 \%$, implying that NGF is capable of inducing a novel heat responsiveness in $\mathrm{C}$ fibers that would normally be heat-insensitive.

\section{Conduction velocity remains unchanged despite the change in axon diameter}

Axonal hypertrophy was most pronounced for the unmyelinated NGF-OE fibers in that their size distribution overlapped more with myelinated control fibers than with unmyelinated control fibers. Such hypertrophy was expected because a previous study showed that trkA-positive sensory neurons were markedly increased in somal size compared with cells expressing other neurochemical markers in NGF-OE mice (Goodness et al., 1997). Both control and NGF-OE mice exhibited significant correlation between axonal diameter and the thickness of the myelin sheath, confirming that size plays an important role in determining which axons become myelinated. This is in agreement with previous
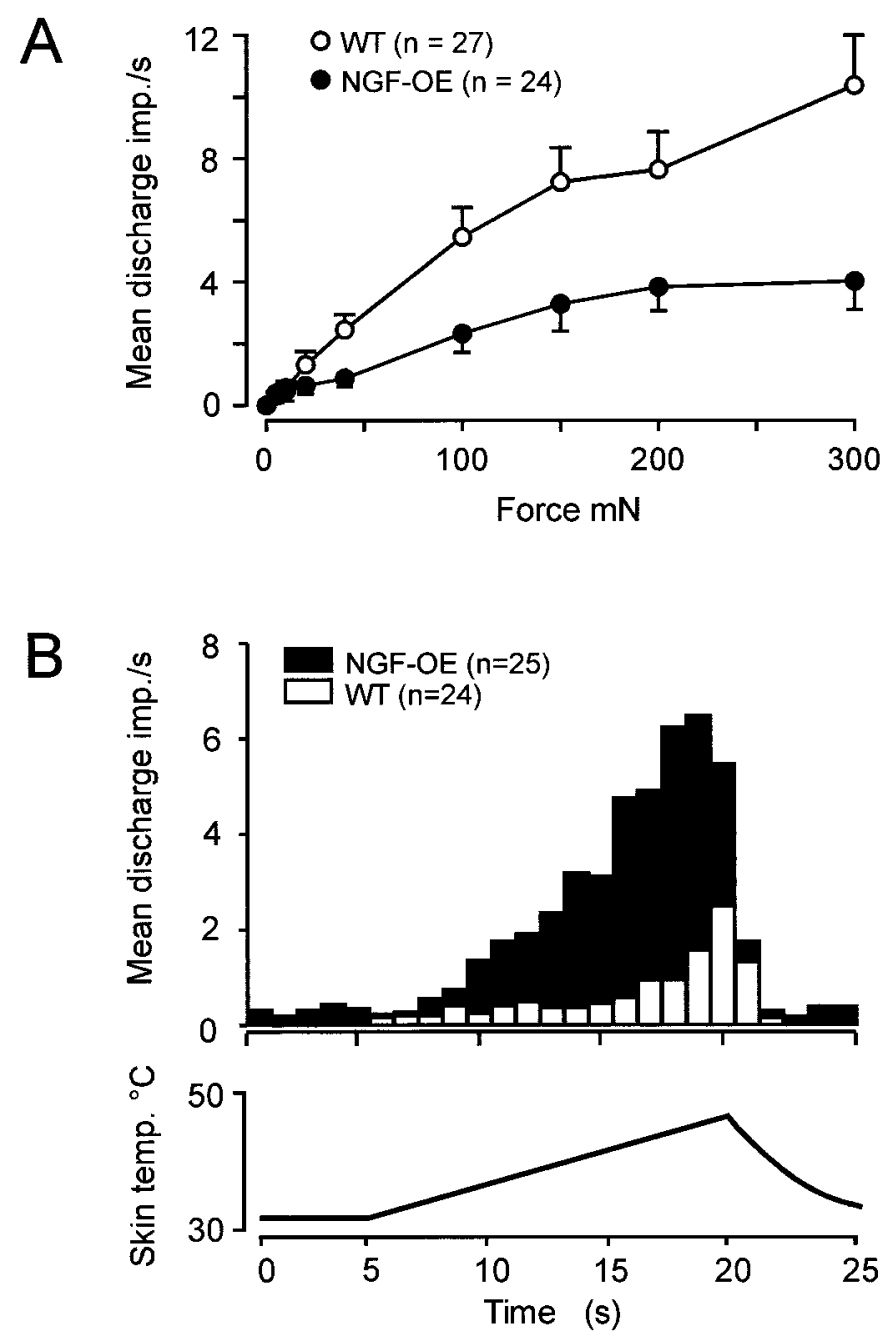

Figure 6. A, Mechanical stimulus-response functions for $\mathrm{C}$ fibers from control and NGF-OE mice. C fibers in NGF-OE mice were significantly reduced in heat responsiveness compared with control mice $\left(F_{(1,389)}=\right.$ $21.8 ; p<0.001$; ANOVA). $B$, Average action potentials per second during $15 \mathrm{sec}$ heat ramp stimulus for all $\mathrm{C}$ fibers tested with heat stimuli. 
studies that have shown that normally unmyelinated axons can induce novel myelination in response to axonal hypertrophy (Voyodic 1989; B. M. Davis, unpublished results). For both NGF-OE and control mice, the apparent threshold for myelination of saphenous axons was $\sim 1 \mu \mathrm{m}$ because no myelinated axons had diameters $<1 \mu \mathrm{m}$ (Fig. $1 A$ ). Because conduction velocity is positively correlated with axon diameter (Arbuthnott et al., 1980; Hoffmeister et al., 1991) the lack of change in the present study was surprising. Because conduction velocity is also correlated to myelin thickness (Waxman, 1980), it is possible that the uniformly thinner myelin sheath in NGF-OE axons relative to controls negates an increase in conduction velocity expected from the increase in axon diameter. In addition the internodal length, as well as the density and efficacy of ion channels, pumps and exchangers at the node of Ranvier have been shown to alter the conduction velocity of an axon (Waxman and Ritchie, 1993), and NGF may alter some of these properties (Lesser et al., 1997).

\section{Differential regulation of the sensitivity of nociceptors to heat and mechanical stimuli}

One of the striking observations of this study was the marked change of the receptive properties of nociceptors, which cannot be attributed to survival effects. The increase of sensitivity was modality-specific in the myelinated and unmyelinated subpopulation. Whereas there was a profound increase in the mechanical sensitivity of myelinated nociceptors, the heat responsiveness remained unchanged. The reverse was found for the unmyelinated nociceptors, which showed a striking increase in their heat sensitivity and a decrease in their mechanical sensitivity. This finding is consistent with the possibility that the mechanisms underlying the heat sensitivity in AM and C fiber nociceptors are differently regulated by the increase of endogenous NGF and that the changes are not the consequence of a general increase of excitability in each fiber population. A differential regulation of the thermal and mechanical sensitivity is also apparent in animals lacking the neurotrophin receptor $\mathrm{p} 75$ in which AM fibers show a reduced heat sensitivity, whereas that of $\mathrm{C}$ fibers is normal (Stucky and Koltzenburg, 1997).

\section{AM fibers}

The increased mechanical responsiveness of AM fibers in NGF-OE mice is in agreement with the finding that treatment of neonatal rats with NGF results in increased sensitivity of AM fibers to mechanical stimuli (Lewin et al., 1993) and could explain, at least in part, the mechanical hyperalgesia that NGF-OE mice display. These results are, however, notably different from the effects of an acute application of NGF, which can induce heat sensitivity in previously insensitive fibers without sensitizing the neurons to mechanical stimuli (Rueff and Mendell, 1996). This indicates that the changes observed in this study cannot easily be explained by a maintained high level of NGF expression in NGF-OE mice.

\section{C fibers}

Functional analysis of $\mathrm{C}$ fibers further confirmed that NGF has an effect on the phenotype of sensory neurons. Virtually every $\mathrm{C}$ fiber was heat-sensitive compared with only $42 \%$ in control mice, and the response magnitude to heat was fourfold greater than in controls. The observation that sensitivity of the same group of fibers to mechanical stimuli was decreased speaks against a global increase of neuronal excitability. These findings are consistent with the observation that postnatal treatment of neonatal rats with NGF increases the proportion of unmyelinated units that responds to heat (Lewin and Mendell, 1994). One possibility why heat sensitivity is differentially regulated by NGF is the fact that the currently known heat transducers in mammals, i.e., vanilloid receptor 1 (VR1) (Caterina et al., 1997) and VR1-like receptor (Caterina et al., 1999), are differentially expressed on small and large neurons (Caterina et al., 1999).

\section{Ongoing activity}

Another striking observation was the finding that $60 \%$ of $\mathrm{C}$ fibers and $29 \%$ of the AM fibers in NGF-OE mice showed ongoing activity. One reason for this may be acute effects of NGF (Koltzenburg et al., 1999). An alternative explanation is that these neurons were sufficiently sensitized to heat to be capable of being activated at $32^{\circ} \mathrm{C}$ (the temperature of the recording bath). However, this is less likely because many heat-insensitive AM fibers also displayed ongoing activity.

In conclusion, the studies presented here confirm for the first time in vivo that target-derived NGF selectively rescues both myelinated and unmyelinated nociceptive neurons but does not rescue low-threshold non-nociceptive sensory neurons. Moreover, the level of endogenous NGF appears to selectively determine the receptive properties of nociceptors and does this differentially for mechanical and thermal sensitivity of neurons with myelinated and unmyelinated fibers.

\section{REFERENCES}

Airaksinen MS, Koltzenburg M, Lewin GR, Masu Y, Helbig C, Wolf E, Brem G, Toyka KV, Thoenen H, Meyer M (1996) Specific subtypes of cutaneous mechanoreceptors require neurotrophin-3 following peripheral target innervation. Neuron 16:287-295.

Albers KM, Wright DE, Davis BM (1994) Overexpression of nerve growth factor in epidermis of transgenic mice causes hypertrophy of the peripheral nervous system. J Neurosci 14:1422-1432.

Arbuthnott ER, Boyd IA, Kalu KU (1980) Ultrastructural dimensions of myelinated peripheral nerve fibres in the cat and their relation to conduction velocity. J Physiol (Lond) 308:125-157.

Baron R, Jänig W, Kollmann W (1988) Sympathetic and afferent somata projecting in hindlimb nerves and the anatomical organization of the lumbar sympathetic nervous system of the rat. J Comp Neurol 275:460-468.

Caterina MJ, Schumacher MA, Tominaga M, Rosen TA, Levine JD, Julius D (1997) The capsaicin receptor: a heat-activated ion channel in the pain pathway. Nature 389:816-824.

Caterina MJ, Rosen TA, Tominaga M, Brake AJ, Julius D (1999) A capsaicin-receptor homologue with a high threshold for noxious heat. Nature 398:436-441.

Crowley C, Spencer SD, Nishimura MC, Chen KS, Pitts-Meek S, Armanini MP, Ling LH, McMahon SB, Shelton DL, Levinson AD, Phillips HS (1994) Mice lacking nerve growth factor display perinatal loss of sensory and sympathetic neurons yet develop basal forebrain cholinergic neurons. Cell 76:1001-1011.

Davies AM, Lumsden AGS (1984) Relation of target encounter and neuronal death to nerve growth factor responsiveness in the developing mouse trigeminal ganglion. J Comp Neurol 223:124-137.

Davies AM, Bandtlow C, Heumann R, Korsching S, Rohrer H, Thoenen H (1987) Timing and site of nerve growth factor synthesis in developing skin in relation to innervation and expression of the receptor. Nature 326:353-358.

Davis BM, Lewin GR, Mendell LM, Jones ME, Albers KM (1993) Altered expression of nerve growth factor in the skin of transgenic mice leads to changes in response to mechanical stimuli. Neuroscience $56: 789-792$.

Davis BM, Albers KM, Seroogy KB, Katz DM (1994) Overexpression of NGF in transgenic mice induce sympathetic projections to primary sensory neurons. J Comp Neurol 349:464-474.

Davis BM, Wang H-S, Albers KM, Carlson SL, Goodness TP, McKinnon D (1996) Effects of NGF overexpression on anatomical and physiological properties of sympathetic postganglionic neurons. Brain Res 724:47-54. 
Davis BM, Fundin BT, Albers KM, Goodness TP, Cronk KM, Rice FL (1997) Overexpression of nerve growth factor in skin causes preferential increases among innervation to specific sensory targets. J Comp Neurol 387:489-506.

Forster C, Handwerker HO (1990) Automatic classification and analysis of microneurographic spike data using a PC/AT. J Neurosci Methods 31:109-118.

Goodness TP, Albers KM, Davis FE, Davis BM (1997) Overexpression of nerve growth factor in skin increases sensory neuron size and modulates trk receptor expression. Eur J Neurosci 9:1574-1585.

Gorin PD, Johnson EM (1980) Effects of long term nerve growth factor deprivation on the nervous system of the adult rat: an experimental autoimmune approach. Brain Res 198:27-42.

Hoffmeister B, Jänig W, Lisney SJW (1991) A proposed relationship between circumference and conduction velocity of unmyelinated axons from normal and regenerated cat hindlimb cutaneous nerves. Neuroscience 42:603-611.

Jhaveri S, Erzurumlu RS, Laywell ED, Steindler DA, Albers KM, Davis BM (1996) Excess nerve growth factor in the periphery does not obscure development of whisker-related patterns in the rodent brain. J Comp Neurol 374:41-51.

Johnson EM, Gorin PD, Brandeis LD, Pearson J (1980) Dorsal root ganglion neurons are destroyed by exposure in utero to maternal antibody to nerve growth factor. Science 210:916-918.

Koltzenburg M, Stucky CL, Lewin GR (1997) Receptive properties of mouse sensory neurons innervating hairy skin. J Neurophysiol 78:1841-1850.

Koltzenburg M, Bennett DLH, Shelton DL, McMahon SB (1999) Neutralization of endogenous NGF prevents the sensitization of nociceptors supplying inflamed skin. Eur J Neurosci 11:1698-1704.

Kress M, Koltzenburg M, Reeh PW, Handwerker HO (1992) Responsiveness and functional attributes of electrically localized terminals of cutaneous C-fibers in vivo and in vitro. J Neurophysiol 68:581-595.

Lawson SN (1992) Morphological and biochemical cell types of sensory neurons. In: Sensory neurons: diversity, development, and plasticity (Scott SA, ed), pp 27-59. New York: Oxford UP.

Lesser SS (1997) Neurotrophins differentially regulate voltage-gated ion channels. Mol Cell Neurosci 10:173-183.

Lewin GR, Barde Y-A (1996) Physiology of the neurotrophins. Annu Rev Neurosci 19:289-317.

Lewin GR, Mendell LM (1994) Regulation of cutaneous C-fiber heat nociceptors by nerve growth factor in the developing rat. J Neurophysiol 71:941-949.

Lewin GR, Ritter AM, Mendell LM (1993) Nerve growth factorinduced hyperalgesia in the neonatal and adult rat. $\mathrm{J}$ Neurosci $13: 2136-2148$.

Mendelson B, Albers KM, Goodness TP, Davis BM (1996) Overexpression of nerve growth factor in epidermis of transgenic mice preserves excess sensory neurons but does not alter the somatotopic organization of cutaneous nerve projections. Neurosci Lett 211:68-72.

Olson L (1967) Outgrowth of sympathetic adrenergic neurons in mice treated with a nerve-growth factor (NGF). Z Zellforsch Mikrosk Anat $81: 155-173$

Reeh PW (1986) Sensory receptors in mammalian skin in an in vitro preparation. Neurosci Lett 66:141-147.

Ritter AM, Lewin GR, Kremer NE, Mendell LM (1991) Requirement for nerve growth factor in the development of myelinated nociceptors in vivo. Nature 350:500-502.

Rueff A, Mendell LM (1996) Nerve growth factor and NT-5 induce increased thermal sensitivity of cutaneous nociceptors in vitro. J Neurophysiol 76:3593-3596.

Ruit KG, Osborne PA, Schmidt RE, Johnson EM, Snider WM (1990) Nerve growth factor regulates sympathetic ganglion cell morphology and survival in the adult mouse. J Neurosci 10:2413-2419.

Smeyne RJ, Klein R, Schnapp A, Long LK, Bryant S, Lewin A, Lira SA, Barbacid M (1994) Severe sensory deficits and sympathetic neuropathies in mice carrying a disrupted Trk/NGF receptor gene. Nature 368:246-249.

Snider WD (1994) Functions of neurotrophins during nervous system development: what the knockouts are teaching us. Cell 77:627-638.

Stucky CL, Koltzenburg M (1997) The low-affinity neurotrophin receptor p75 regulates the function but not the selective survival of specific subpopulations of sensory neurons. J Neurosci 17:4398-4405.

Stucky CL, DeChiara T, Lindsay RM, Yancopoulos GD, Koltzenburg M (1998) Neurotrophin 4 is required for the survival of a subclass of hair follicle receptors. J Neurosci 18:7040-7046.

Voyodic JT (1989) Target size regulates calibre and myelination of sympathetic axons. Nature 342:430-433.

Waxman SG (1980) Determinants of conduction velocity in myelinated nerve fibers. Muscle Nerve 3:141-150.

Waxman SG, Ritchie JM (1993) Molecular dissection of the myelinated axon. Ann Neurol 33:121-136. 